\title{
THE EFFECT OF ECONOMIC EVENTS ON VOTES FOR PRESIDENT: 1984 Update
}

\section{Ray C. Fair}

In previous work I have developed an equation explaining votes for president in the United States that seems to have remarkable explanatory power. In this paper the equation is updated through the 1984 election and then used to predict the 1988 election.

In previous work I have developed an equation explaining votes for president in the United States that seems to have remarkable explanatory power. The purpose of this paper is to update this equation through the 1984 election and then use it to predict the 1988 election.

The history of the equation is as follows. The original work was done in 1976 and published in Fair (1978). In this work I tested a fairly wide range of theories of voting behavior, from the sophisticated and well informed voters of Stigler (1973) to the somewhat naive voters of Kramer (1971). The two main issues examined regarding the effect of economic events on votes for president were (1) how far back voters look in evaluating the economic performance of the two parties and (2) what economic variables voters use in evaluating performance. The results supported the view that voters look only at the economic performance of the current party in power, not also, for example, the performance of the opposition party the last time it was in power. The most important economic variable was the growth uate of real per capita GNP somewhere between about six months and a year before the election. The data did not appear to be sufficient to distinguish between the time periods of six months, nine months, and a year before the election. The rate of inflation in the two year period before the election had a small (negative) effect on votes for president, although it was not statistically significant. The sample period used for this work was 1916-1976, consisting of 16 elections.

In Fair (1982) the equation was updated through the 1980 election. From

Fay C. Fair, Cowles Foundation, Box 2125, Yale Station, New Haven, CT 06520. 
a statistical point of view the 1980 election was a good observation. The growth rate of real GNP six months before the election was somewhat different from the growth rate one year before the election $(-5.7 \%$ versus $-2.9 \%$ ). This helps break the collinearity between the two variables and may help in determining which time period is the relevant one. Also, the rate of inflation prior to the 1980 election was high by historical standards, and this increased variance may help in deciding the effects of inflation on voting behavior. The results for the growth rate provided support for the six month period over the nine month period and over the one-year period. The results for the inflation variable were stronger than before, although the variable was still not in general statistically significant.

\section{THE EQUATION}

The 1984 election increases the sample size from 17 to 18 and may allow a few more tests to be performed. I will first present the "final" version of the equation and then discuss the various tests that were performed in arriving at this version. The following variables are used (all growth rates are at annual rates in percentage points):

$V=$ Democratic share of the two-party vote.

$g=$ growth rate of real per capita GNP in the second and third quarters of the election year.

$p=$ absolute value of the rate of inflation in the two year period prior to the election. ${ }^{1}$

DPER $=1$ if there is a Democratic incumbent and he is running for election, -1 if there is a Republican incumbent and he is running for election, 0 otherwise.

$I=1$ if there is a Democratic incumbent, -1 if there is a Republican incumbent.

$t=$ time trend: 8 in 1916, 9 in 1920, ., 25 in 1984.

The estimated equation for 1916-1984, estimated by ordinary least squares, is $\left(t\right.$-statistics are in parentheses) $:^{2}$

$$
\begin{aligned}
& V=.4073+.0049 \cdot I+.0449 \cdot D P E R \\
& \text { (11.73) } \quad(0.29) \\
& +.0033 \cdot t+.0102 \cdot g \cdot I-.0034 \cdot p \cdot I \\
& \mathrm{SE}=.0310, \quad R^{2}=.887, \quad \mathrm{DW}=2.27
\end{aligned}
$$

The actual and predicted values of $\mathrm{V}$ are given in Table 1. 
TABLE 1. Actual and Predicted Values of $V$

\begin{tabular}{lccccccccc}
\hline Year & 1916 & 1920 & 1924 & 1928 & 1932 & 1936 & 1940 & 1944 & 1948 \\
\hline Actual & .517 & .361 & .457 & .412 & .591 & .625 & .550 & .538 & .524 \\
Predicted & .522 & .352 & .415 & .448 & .575 & .633 & .573 & .570 & .513 \\
Error & .005 & -.009 & -.042 & .036 & -.016 & .008 & .023 & .032 & -.011 \\
& & & & & & & & & \\
Year & 1952 & 1956 & 1960 & 1964 & 1968 & 1972 & 1976 & 1980 & 1984 \\
\hline Actual & .446 & .422 & .501 & .613 & .496 & .382 & .511 & .447 & .408 \\
Predicted & .456 & .437 & .492 & .542 & .509 & .396 & .497 & .447 & .425 \\
Error & .010 & .015 & -.009 & -.071 & .013 & .014 & -.014 & .000 & .017 \\
\hline
\end{tabular}

Equation (1) has the following properties. When the president himself (hopefully herself at some future times) is running, he has an advantage of 4.49 percentage points. The party in power itself has only a slight advantage $\langle 0.49$ percentage points $\rangle$, and it is not statistically significant. The growth rate coefficient is .0102 , which means that every one percentage point increase in the growth rate leads to a 1.02 percentage point increase in the vote share for the incumbent party. The inflation rate coefficient is -.0034 , which means that every one percentage point increase in the inflation rate leads to a 0.34 percentage point fall in the vote share for the incumbent party.

The coefficient of the time trend is positive, which means that there is a trend over time in favor of the Democrats. On the other hand, the equation does indicate that the Republicans have had a head start over the sample period, holding the incumbency information and the economic variables constant. For example, the value of $t$ in 1916 is 8 , and ignoring all variables in the equation except the constant term and the time trend, the predicted value for the Democrats is $.4073+.0033 .8=.4337$, which gives the Republicans a head start of 6.63 percentage points. In 1984 the value of $t$ is 25 , and the predicted value for the Democrats is $.4073+.0033 .25=.4898$, which is a head start for the Republicans of 1.02 percentage points. The Republican head start is thus getting smaller over time.

The explanatory power of the equation seems quite remarkable. The estimated standard error is 3.1 percentage points, and there is only one election in which the error is quite large, which is the Johnson-Goldwater election of 1964 . The equation predicted Johnson to win with $54.2 \%$ of the vote, when in fact he got $61.3 \%$, which is an error of 7.1 percentage points. Otherwise, there is only one other election in which the error is greater than 4.0 percentage points, which is the Davis-Coolidge election of 1924 , with an error of 4.2 percentage points. There are three elections in which the winner was predicted wrong: Kennedy-Nixon in 1960, Humphrey- 
Nixon in 1972, and Carter-Ford in 1976. The errors in these three cases are, however, quite small. The elections were very close, and the equation predicted them to be very close.

The Reagan victories in 1980 and 1984 were predicted very well, and it is easy to see why. In 1980 the growth rate was $-5.7 \%$ and the inflation rate was $9.0 \%$. Even though Carter had the incumbency advantage, the economy was way against him and Reagan was predicted to be an easy winner. In 1984 the growth rate was $2.7 \%$, the inflation rate was $3.7 \%$, and Reagan had the incumbency advantage, all of which adds up to a sizable Reagan victory. Note that one need not appeal to Reagan's personality to explain his large victory margins.

\section{Tests of the Equation}

Various alternative specifications and tests of Equation (1) will now be discussed. For the first test the growth rate of real per capita GNP in the third quarter only of the election year was added to the equation. (g, the growth rate in the second and third quarters of the election year, was left in the equation.) The coefficient estimate of this new variable was -.0026 , with a $t$-statistic of -0.42 . The coefficient estimate of $g$ was .0124 , with a $t$-statistic of 2.18. This is clear evidence in favor of the growth rate in the six month period before the election over the growth rate in the three month period before.

For the second test the growth rate in the first, second, and third quarters of the election year was added to the equation. Its coefficient estimate was .0059 , with a $t$-statistic of 0.80 . The coefficient estimate of $g$ was .0045 , with a $t$-statistic of 0.61 . In this case no decision can be made regarding the better time period; the data cannot discriminate between the two variables. I have chosen to use the growth rate in the six month period as the basic growth rate variable, partly because this is the variable that was used for the main results in Fair (1982), but one could with just as much confidence use the growth rate in the nine-month period.

For the third test the growth rate in the four quarters before the election was added. Its coefficient estimate was .0021 , with a $t$-statistic of 0.31 . The coefficient estimate of $g$ was .0083 , with a $t$-statistic of 1.23 . Although $g$ is not significant, its coefficient estimate is much larger than the coefficient estimate of the four quarter growth rate, and the results do favor $g$. The overall evidence thus suggests that the relevant time period is somewhere between two and three quarters before the election.

For the fourth test the inflation rate in the one year-period before the election was added $(p$, the inflation rate in the two-year period before the election, was left in the equation). The coefficient estimate of the new 
inflation variable was -.0004 , with a $t$-statistic of -0.08 . The coefficient estimate of $p$ was -.0031 , with a $t$-statistic of -0.60 . For the fifth test the inflation rate in the three year period before the election was added. Its coefficient estimate was .0002 , with a $t$-statistic of 0.03 . The coefficient estimate of $p$ was -.0036 , with a $t$-statistic of -0.54 . It is thus clear that $p$ wins out, although again $p$ is not statistically significant in Equation (1).

The hypothesis that U.S. involvement in wars has an effect on voting behavior was tested in Fair (1978). The ratio of the size of the armed forces to the total population was taken as a measure of U.S. involvement, and this variable was tried in the estimation work. The percentage change in this variable in various periods before the election had a slight negative effect on votes for president, although it was not statistically significant. The same is true in the present case. When the percentage change in the ratio of the armed forces to the population in the two year period prior to the election was added to Equation (1), its coefficient estimate was -.0050 , with a $t$-statistic of -1.67 . The coefficient estimate of $g$ was .0105 , with a $t$-statistic of 5.46, and the coefficient estimate of $p$ was -.0053 , with a $t$-statistic of -1.74 . There is thus at least some slight evidence that U.S. involvement in wars has a negative effect on voting behavior. Regarding the time period before the election, almost identical results were obtained for the percentage change three quarters before the election, one year before, and two years before. These periods produced better results than did the oneand two-quarter periods before the election.

When the same person runs in more than one election, there is a chance of trying to estimate his personality effect or "independent vote getting ability" (VGA). In Fair (1978) I attempted to account for the VGA of people who ran more than once through a series of assumptions that led to restrictions on the covariance matrix of the error term in Equation (1). There was some slight evidence that some VGA effects were being picked up in the estimates, but the results were not very strong. For the current estimates no VGA effects could be found, ${ }^{3}$ and so this attempt has been dropped.

With only 18 observations there is always the danger of data mining, i.e., finding relationships that seem good statistically but are in fact spurious. One could, for example, create an "extremist" dummy variable that, say, was one for Goldwater and zero for everyone else. If this variable were added to Equation (1), it would improve the fit considerably, since it would get rid of the large error in 1964. Since each election has special circumstances, enough variables could undoubtedly be found to achieve a perfect fit. I have avoided using dummy variables except the incumbency variables. The aim has been to keep the equation as parsimonious as possible. I have, however, done one thing that is possibly in the nature of using a dummy variable to improve the fit of the equation, which concerns 
the DPER variable. The question is how to treat people who were running for election at the time they were president, but who took over the presidency because of a death or resignation. I have given these people a value of one if they were the vice presidential candidate on the ticket that got elected. This includes everyone except Ford, who was appointed vice president and then became president when Nixon resigned. If instead I count Ford as an incumbent running for election, the equation makes a larger error for 1976. Equation (1) already predicts a slight Ford victory, and the predicted victory margin becomes larger if Ford is counted as an incumbent running for election. This change does not, however, have much effect on the coefficient estimates, and so fortunately it does not matter very much which option is used (aside from the size of the error in 1976).

It was noted above that the time trend in Equation (l) is picking up a trend in favor of the Democrats over time. It is obviously not sensible to extrapolate this trend forever, and at some point it should be cut off. In future work, especially after one or two more observations become available, it will be interesting to stop the growth of the time trend in various years and see which gives the best results. It may be by now, for example, that whatever factors were causing the movement in favor of the Democrats have stopped. Given the limited size of the sample, it seemed somewhat premature to examine this question, and no experimentation was done regarding different time variables. For the predictions for the 1988 election, discussed later in this paper, $t$ has been increased by 1 (to 26 ).

Finally, an important test of an equation is how stable the coefficient estimates are to changes in the sample period. The following are the results of estimating Equation (1) over the period 1916-1968, which consists of 14 elections:

$$
\begin{aligned}
& \mathrm{V}=.3968+.0050 \cdot I+.0386 \cdot D P E R \\
& \text { (8.82) (0.25) (1.70) } \\
& +.0042 \cdot t+.0101 \cdot g \cdot I-.0030 \cdot p \cdot I, \\
& (-0.71) \\
& \mathrm{SE}=.0362, \quad R^{2}=.867, \quad \mathrm{DW}=2.42
\end{aligned}
$$

The predicted values for the elections beyond the estimation period are as given in Table $2 .{ }^{4}$ It is clear that the results for Equation (2) are similar to those for Equation (1); the last four elections have made little difference to the basic results. The coefficient estimates have changed very little, and the predicted values are similar. The winner of the 1976 election is predicted correctly by Equation (2), contrary to the case for Equation (1), although the errors for both equations are quite small in size. 
TABLE 2. Predicted Values for the Elections

\begin{tabular}{lcrcc}
\hline Values & 1972 & 1976 & 1980 & 1984 \\
\hline Actual & .382 & .511 & .447 & .408 \\
Predicted & .409 & .503 & .456 & .442 \\
Error & .027 & -.008 & .009 & .034 \\
\hline
\end{tabular}

\section{THE PREDICTIVE ABILITY OF THE EQUATION}

The predictions presented in the previous section are based on the actual values of the growth rate $(g)$ and the inflation rate $(p)$. These are not predictions that could have been made, say, six months before the election, because the actual values of $g$ and $p$ are not known six months before.

Lewis-Beck and Rice (1984)-LR-present a "forecasting" equation for presidential elections, where the two explanatory variables are the growth rate in real per capita GNP in the first quarter of the election year and the percentage approving the president's handling of his job in the May Gallup poll of the election year. Both of these variables are known six months before the election, and so predictions from this equation could have been made six months before. The mean absolute prediction error for this equation for the nine elections between 1948 and 1980 is 2.48 percentage points (Lewis-Beck and Rice, 1984, p.17). The mean absolute prediction error for Equation (1) above for these nine elections is 1.74 percentage points. Equation (1) is thus on average more accurate than the LR forecasting equation, given the actual values of $g$ and $p$.

In order to examine the pure forecasting accuracy of Equation (1), I used as values for $g$ and $p$ the median predicted values from the ASA/NBER survey of business forecasters. The values are from the survey taken in late April of each election year. The median predicted values from this survey are good measures of the "consensus" forecasts at any one time. Data are available beginning with the 1972 election. 5 The predicted values of $g$ compared to the actual values are 5.9 versus 5.1 for $1972,4.4$ versus .8 for $1976,-5.9$ versus -5.7 for 1980 , and 2.6 versus 2.7 for 1984 . The predicted values of $p$ compared to the actual values are 5.1 versus 5.2 for $1972,7.6$ versus 7.6 for $1986,9.1$ versus 9.0 for 1980 , and 4.1 versus 3.7 for 1984 . The predicted values of $p$ are quite accurate because $p$ is the average rate of inflation over the two-year period before the election, and so by April of the election year actual values for six of the eight quarters are available. The predicted values for $g$ are fairly accurate except for 1976 , where the growth rate was overpredicted by 3.6 percentage points.

The predicted values from Equation (1) using the ASA NBER values are 
as given in Table 3 . These predicted values are close to the ones using the actual values of $g$ and $p$ except for 1976, where the error is now -5.1 instead of -1.4 . Given the larger predicted value of $g$, the equation predicted more votes for the incumbent Ford (and thus a smaller Democratic share). The mean absolute error for the three elections 1972, 1976 , and 1980 is 1.93 percentage points, which compares to 2.73 percentage points for the LR forecasting equation for these three elections. Therefore, for these three elections at least, Equation (1) combined with the ASA/NBER predictions seems to be a more accurate forecasting device than the LR equation. This is, of course, a very small sample to base any conclusion upon, but the results are at last encouraging for Equation (1).

Both Equation (1) and the LR equation are estimated through the end of the forecast period, and so the forecasts just cited are "within-sample" predictions. It was seen in the previous section, however, that the coefficient estimates of Equation (1) are fairly stable to shortening the estimation period by four observations. The results in Lewis-Beck and Rice (1984) also indicate that the LR equation is fairly stable in this sense. The above comparisons are thus not likely to be sensitive to the use of within-sample predictions.

It should perhaps be emphasized, as Lewis-Beck and Rice are aware, that Equation (1) and the LR equation are quite different types of equations. Equation (1) is a "causal" equation. It postulates that the state of the economy (as measured by $g$ and $p$ ) causes voters to vote the way they do. In other words, Equation (1) "explains" the way voters behave. The LR equation, on the other hand, because of the use of the Gallup survey data, is not causal. It cannot be said that the survey variable causes voters to vote the way they do; the survey is simply picking up people's views about the president six months before the election, views that turn out to be correlated with their actual voting behavior six months later. The surveys are sampling something that is similar to what is revealed on election day in the way people vote. For the model to be causal, one would need to explain (in a second equation) the factors that affect the answers to the survey. The LR equation is a perfectly legitimate forecasting equation, but it does not

TABLE 3. Predicted Values from Equation (1) Using ASA/NBER Values

\begin{tabular}{lrrrr}
\hline Values & 1972 & 1976 & 1980 & 1984 \\
\hline Actual & .382 & .511 & .447 & .408 \\
Predicted & .388 & .460 & .446 & .428 \\
Error & .006 & -.051 & -.001 & .020 \\
\hline
\end{tabular}


explain voting behavior in the deep sense of explaining. The same is true of Tufte's equation (1978, Table 5-6, p. 122), which uses a survey variable regarding people's likes and dislikes of the presidential candidates. The same is also true of Rosenstone's (1983) equation, which includes variables like a survey estimate (for 1952 and 1968) of the proportion of the population who opposed the incumbent's handling of the war and a Gallup survey estimate (for 1980) of the percentage of people who think the Democrats will better provide peace divided by the percentage who think the Republicans will better provide peace (Rosenstone, 1983, pp. 185-186).

Finally a few points should be made about my 1976 and 1980 predictions. I noted in Fair $(1978, \mathrm{fn}$. 13) that about a year prior to the 1976 election I made a prediction with an equation similar to Equation (1) that the Democrats would get $44 \%$ of the two-party vote. The actual value was $51.1 \%$, which is an error of 7.1 percentage points. This figure is also cited in Rosenstone (1983). How can this error be explained in light of the small error of 1.4 percentage points for Equation (1) above? There are two main reasons. The first, as mentioned in the previous section, is that I am now not counting Ford as an incumbent running for reelection, whereas I did for the forecast in 1976. One may, of course, consider this to be an element of data mining. The second, as noted in footnote 2 , is that the final revised value of $g$ for 1976 is $0.8 \%$, whereas the value I used for the forecast was closer to the first estimate of about $3.4 \%$. A third, less important, reason is that the equation used in 1976 had slightly different coefficient estimates than those in Equation (1) above because it was only estimated through the 1972 data.

Regarding the 1980 election, Rosenstone (1983) cites me as predicting a Democratic share of .480 , which compares to the actual value of .447 . This is an error of 3.3 percentage points compared to 0.0 percentage points for Equation (1) above. In this case the difference is simply due to different values of $g$ and $p$ used (from the actual values) and to slightly different coefficient estimates because the equation was only estimated through 1976.

\section{PREDICTING THE 1988 ELECTION}

Given the values of $g$ and $p$, Equation (1) can be used to predict the 1988 election. Reagan will not be running, and so DPER is zero. Table 4 gives the predicted values for $V$ for alternative values of $g$ and $p$. If, for example, the inflation rate turns out to be $4.0 \%$ and the growth rate to be $2.0 \%$, which are roughly the consensus predictions at the time of this writing (July 1987), the Democrats are predicted to get $48.2 \%$ of the vote, which implies a close election. Contrary to the 1984 election, where Reagan seemed a sure winner early on, the 1988 election seems too close to call for plausible values of $g$ and $p$ at the moment. ${ }^{6}$ 
TABLE 4. Predicted Democratic Share of the Two-Party Vote for 1988

\begin{tabular}{ccccccccc}
\hline Growth & \multicolumn{7}{c}{ Inflation Rate $(p)$} \\
\cline { 2 - 9 } Rate $(g)$ & $0 \%$ & $1 \%$ & $2 \%$ & $3 \%$ & $4 \%$ & $5 \%$ & $6 \%$ & $.7 \%$ \\
\hline$-6 \%$ & .550 & .553 & .557 & .560 & .564 & .567 & .570 & .574 \\
$-5 \%$ & .539 & .543 & .546 & .550 & .553 & .557 & .560 & .564 \\
$-4 \%$ & .529 & .533 & .536 & .540 & .543 & .547 & .550 & .553 \\
$-3 \%$ & .519 & .522 & .526 & .529 & .533 & .536 & .540 & .543 \\
$-2 \%$ & .509 & .512 & .516 & .519 & .523 & .526 & .530 & .533 \\
$-1 \%$ & .499 & .502 & .505 & .509 & .512 & .516 & .519 & .523 \\
$0 \%$ & .488 & .492 & .495 & .499 & .502 & .506 & .509 & .513 \\
$1 \%$ & .478 & .482 & .485 & .488 & .492 & .495 & .499 & .502 \\
$2 \%$ & .468 & .471 & .475 & .478 & .482 & .485 & .489 & .492 \\
$3 \%$ & .458 & .461 & .465 & .468 & .471 & .475 & .478 & .482 \\
$4 \%$ & .447 & .451 & .454 & .458 & .461 & .465 & .468 & .472 \\
$5 \%$ & .437 & .441 & .444 & .448 & .451 & .454 & .458 & .461 \\
$6 \%$ & .427 & .430 & .434 & .437 & .441 & .444 & .448 & .451 \\
\hline
\end{tabular}

\section{CONCLUSIONS}

The results of any study based on 18 observations must be interpreted with considerable caution. The basic equation of this paper has, however, held up well during the past four elections, and it seems worth taking seriously. In his survey of vote and popularity (VP) functions, Paldam (1981, p. 194) concludes that "the VP-function is a fairly unstable one." The results in the present paper suggest that this conclusion is not true for Equation (1), i.e., for the vote function for U.S. presidential elections. This is not to say, of course, that popularity functions are also stable. As Paldam notes (p. 188), a brief answer to a survey question is not necessarily the same thing as a possibly well considered decision on how to vote. Vote functions for congressional elections may also not be stable if, as argued in Fair (1978), voters are more likely to hold the party in the White House (rather than the party that controls Congress if two are different) responsible for the state of the economy. At any rate, the vote function in this paper seems quite stable.

The present results suggest that voters look back between about six and nine months regarding the real growth rate and about two years regarding the inflation rate. This rather short horizon leaves room for an administration to manipulate the economy to increase the chances of its party getting reelected. Whether administrations in fact behave this way, thus creating "political business cycles," is, of course, a different question from the one considered here. The only point here is that voters seem to behave in a way that provides an incentive for such manipulation. 


\section{NOTES}

1. Let $P$ be the price level. For an election in year $t, p$ is $\left[\left(P_{3 t} / P_{3 t-2}\right)^{5}-1\right] \cdot 100$, where $P_{3 t}$ is the price level in the third quarter of year $t$ and $P_{3 t-2}$ is the price level in the third quarter of year $t-2$.

2. The National Income Accounts data that are used for $g$ and $p$ are revised back periodically by the Department of Commerce. The latest revised data were used for the estimation of Equation (1), and this is another reason (aside from the addition of the 1984 observation) that the equation will differ from previously estimated ones. The data revisions can be fairly large. For the work in Fair (1978) the value of $g$ for the 1976 election was 3.4, whereas in Fair (1982) the value was 1.7. The value used in this paper is 0.8 . In Fair (1982) the value of $g$ for the 1980 election was -4.9 , whereas in this paper the value is -5.7 . The revisions in $p$ have been smaller. For the 1976 election the value of $p$ was 7.2 in Fair (1978), 7.2 in Fair (1982), and 7.6 in this paper. For the 1980 election the value of $p$ was 8.7 in Fair (1982) and 9.0 in this paper.

Note that by always using the latest revised data the implicit assumption is being made that revised data better approximate the economic conditions known to the voters. Voters are assumed not to look at the published numbers in deciding how to vote, but rather at the actual conditions around them.

3. The estimates of $\lambda$ were almost always zero in the present case, where $\lambda$ is defined in Fair (1978, p. 16.3).

4. These predictions, like the ones for Equation (1), are based on the actual values of the right-hand side variables.

5. I am indebted to Stephen K. McNees of the Federal Reserve Bank of Boston for supplying me with these data. The growth rate forecasts from the ASANBER survey are for total real GNP, not per capital real GNP. For the predicted values of $g$ used in this study, I subtracted from the ASA/NBER predicted growth rate the actual growth rate of population. Population is quite easy to forecast six months ahead, and so the use of the actual values in this case seems reasonable.

6. In Fair (1982, p. 324) I presented a similar table for the 1984 election, based on the estimated equation at the time. Given the actual values of $g$ and $p$ of 2.7 and 3.7 , respectively, the predicted value from the table (interpolated) is .441 , which compares to the actual value of .408 . The election was thus predicted quite well. Note that this predicted value of .441 differs from the predicted value of .425 presented after Equation (1) above because of the reestimation of Equation (1) through the latest data.

\section{REFERENCES}

Fair, Ray C. (1978). The effect of economic events on votes for president. The Review of Economics and Statistics, 60 (May): 159-173.

Fair, Ray C. (1982). The effect of economic events on votes for president: 1980 results. The Review of Economics and Statistics, 64 (May): 322-325.

Kramer, Gerald H. (1971). Short-term fluctuations in U.S. voting behavior, 18961964. The American Political Science Review, 65 (March): 131-143.

Lewis-Beck, Michael S., and Rice, Tom W. (1984). Forecasting presidential elections: A comparison of naive models. Political Behavior 6 (January): 9-21.

Paldam, Martin (1981). A preliminary survey of the theories and findings on vote and popularity functions. European Journal of Political Research 9 (June) 181-199. 
Rosenstone, Steven J. (1983). Forecasting Presidential Elections. New Haven: Yale University Press.

Stigler, George J. (1973). General economic conditions and national elections. The American Economic Review, 63 (May): 160-167.

Tufte, Edward R. (1978). Political Control of the Economy. Princeton, NJ: Princeton University Press.

APPENDIX

\begin{tabular}{lcrrrrr}
\hline Year & $V$ & $I$ & $D P E R$ & $g$ & $p$ & \multicolumn{1}{c}{$a$} \\
\hline 1916 & .5168 & 1 & 1 & 6.38 & 7.73 & 3.89 \\
1920 & .3613 & 1 & 0 & -6.14 & 8.01 & -64.38 \\
1924 & .4568 & -1 & -1 & -2.16 & 0.62 & -3.41 \\
1928 & .4124 & -1 & 0 & -0.63 & 0.81 & -0.15 \\
1932 & .5914 & -1 & -1 & -13.98 & 10.01 & -2.64 \\
1936 & .6247 & + & 1 & 13.41 & 1.36 & 6.70 \\
1940 & .5500 & 1 & 1 & 6.97 & 0.53 & 24.99 \\
1944 & .5378 & 1 & 1 & 6.88 & 1.98 & 67.35 \\
1948 & .5237 & 1 & 1 & 3.77 & 10.39 & -36.19 \\
1952 & .4460 & 1 & 0 & -0.34 & 2.66 & 51.69 \\
1956 & .4224 & -1 & -1 & -0.69 & 3.59 & -9.34 \\
1960 & .5009 & -1 & 0 & -1.92 & 2.16 & -4.31 \\
1964 & .6134 & 1 & 1 & 2.38 & 1.73 & -2.66 \\
1968 & .4960 & 1 & 0 & 4.00 & 3.94 & 5.13 \\
1972 & .3821 & -1 & -1 & 5.05 & 5.17 & -13.53 \\
1976 & .5105 & -1 & 0 & 0.78 & 7.64 & -2.65 \\
1980 & .4470 & 1 & 1 & -5.69 & 8.99 & -1.35 \\
1984 & .4083 & -1 & -1 & 2.69 & 3.68 & 0.06 \\
\hline
\end{tabular}

Notes: Variables are defined in the text except for $a$. Remember that $p$ is the absolute value of the rate of inflation. $a$ is the percentage change in the ratio of the armed forces to the population (at an annual rate in percentage points) in the two-year period before the election. 